\title{
A FRENCH HIGHER EDUCATION IT PROJECT
}

\author{
Marc Bouchara ${ }^{1}$ \\ ${ }^{1}$ Amue, 34 rue Henri Noguères, 34098 Montpellier, France, marc.bouchara@amue.fr
}

Keywords

Urbanization of IS - urbanized IT, System integration, PRISME Project, Master Data Management (MDM), Enterprise Application Integration (EAI), Roll-out, Universities - Higher Education Institutions.

\section{ABSTRACT}

Amue, created in 1992, is a French shared-services Agency for Universities and other Higher Education and Research Institutions. It is a public consortium partly funded by the French Government and partly by its members. The board of the Agency is directly led by HE institutions through the 'Conférence des Présidents d'Université' (CPU: Conference of French University Rectors). Amue intervenes as an advisor for its members and supports them in various fields: governance, management, financial and tax accounting, human resources, students management, research, real estate management, international relations and information systems.

The five-year strategic plan (2012-2016) of the agency sets 3 priorities:

1. Urbanization of the Information System and optimization of solutions

2. Training and skills development

3. Monitoring, expertise, representation and procurement

The presentation which will be made during EUNIS 2013 congress will focus on a project called 'Prisme', which is Amue's urbanization and system integration solution. 'Prisme' aims at enhancing communication between each IS breed (using EAl component) via a new data repository (using MDM component), in order to improve data quality of the whole IS of our members.

\section{System Integration, urbanization process and the 'Prisme' project}

Since its foundation, Amue used a "best of breed" approach to build its solutions, thus granting HEI solutions fitting their needs and business processes. However, this approach also induces that the different information systems operate in silos, and it brings about a key issue as to the way data is shared among the respective repositories of the various information system breeds.

This approach also implies that Amue and its members develop multiple specific interfaces in a 'point to point' mode. This implies considerable extra costs and makes the maintenance of this 'spaghetti-ware' very difficult.

Meanwhile, the delivery of four new solutions in the next three years will render this situation even more complex and problematic as, ultimately, it may weaken the overall quality of our solutions.

Thus, the implementation of 'Prisme' will be a concrete and effective answer to deal with these constraints. Its purpose is to create a system integration platform allowing our whole solution to be interfaced and integrated. Without any doubts, offering a single global, integrated, urbanized and tested information system will improve the quality of our deliveries.

In this respect, Amue will not only focus on editing solutions but will also guaranty their full integration (editor AND integrator).

\section{A few words about Prisme:}

In order to trigger a comprehensive urbanization, the project complies with two major objectives, no matter the nature of the bricks composing the information system (Amue's or other editors' IS):

- Management of the reference data of the information system (Master Data Management) 
- Centralized device managing exchanges and flows of all IS for the reference data but also for any kind of exchanges necessary between the different bricks of the IS (business flows, data bus, etc.) - (EAI Enterprise Application integration)

This couple MDM/EAl will gradually be positioned at the core of the information system and forthcoming solutions will have to fit within this framework

- MDM : stakes and needs

- Provide a global coherence for IS data

- Ensure uniqueness of data reference

- Bring visibility and availability of Master Data

- Increase productivity and agility of business processes using the reference data

- Improve quality of operational and decision-making data

- Secure access to the reference data

- EAl : stakes and needs

- Provide agility and flexibility for the entire IS

- Loosen coupling between applications in order to facilitate their evolution

- Decrease costs of specific flow developments

- Optimize supervision and administration of all exchanges in the entire IS

- Facilitate IS integration despite its possible heterogeneity

- Build a single catalog of services provided by the IS through a "bus of services"

\section{AUTHORS' BIOGRAPHIES}

Marc Bouchara has been Deputy CEO of Amue since 2012. He has an extensive experience working in the Information System and Technology sector gained both from the public and private sectors. For almost ten years, he has held executive positions within two major IT groups in France (Sema and Capgemini).

He then decided to serve the public sector where he worked as $\mathrm{CIO}$ for different local authorities in order to establish an e-government project. He also carried out different activities as a consultant for the Information System sector and he monitored international ventures in this field.

Since 2012, he has been involved in several activities related to Information Systems in the Higher Education and Research sector. Among these endeavors, the most challenging are the development of a Digital University and the ways of enhancing security of university's Information Systems. 